(Aus der medizinischen Klinik der Universität Tübingen.)

\title{
Bemerkungen zu der Mitteilung von Y. Henderson.
}

\author{
(Pflüger's Archiv Bd. 147 S. 111.) \\ Von
}

Dr. Hermann Stranb, Assistenzarzt.

Dass es mir vollständig fernlag, Henderson's Verdienste um die Herzphysiologie schmälern zu wollen, geht wohl aus meiner englischen Arbeit zur Genüge hervor, in der ich auf seine Arbeit ausführlich eingegangen bin und wesentliche Punkte zum Teil wörtlich zitiert habe (S. 378). Auf das schärfste muss ich aber der Darstellung Henderson's widersprechen, die bei Unkenntnis der beiden Originalarbeiten den Anschein erweckt, dass ich Henderson's Resultate übernommen habe. Henderson hat seine Volumregistrierung mit einem $\mathrm{M}$ areytambour und Hebelvergrösserung, seine Druckregistrierung mit einer von der Karotis in den Ventrikel eingeführten Sonde ausgefübrt. Aus den in meinen Arbeiten eingehend erörterten Gründen sind diese Methoden wegen der zu grossen Masse, der dementsprechend notwendigen zu grossen Dämpfung und wegen des für Volumregistrierung zu grossen Elastizitätskoeffizienten der verwendeten Registrierinstrumente ungeeignet, irgendwelche zuverlässigen Schlüsse auf die Art der Volumkurve und des Druckablaufs zu begründen. Es gilt für die Untersuchungen Henderson's alles, was ich im Journ. of Physiol. 40, 1910, S. 379-382 und in diesem Archiv 143, 1911, S. 69-72 ganz allgemein gesagt habe.

Das Neue meiner Untersuchungen aus dem Institute of Physiology des University College in London und aus der medizinischen Klinik Tübingen liegt in einer neuen Methodik, die, wie ich gezeigt zu haben glaube, Volum und Innendruck obne Entstellung der Karven registriert. Über diesen springenden Punkt der ganzen Frage geht Henderson schweigend hinweg. Die Ansichten Henderson's 
stimmen auch, wie eine Lektüre der Originalarbeiten zeigt, mit den meinigen in wesentlichen Punkten nicht überein.

Wie Henderson dazu kommt, seine Arbeit als die Quelle meiner methodisch völlig abweichenden Untersuchung zu bezeichnen, ist mir unerfindlich. Selbstverständlich steht jeder spätere Untersucher auf den Schultern seiner Vorgänger. Mit allem Nachdruck aher behaupte ich die völlige Originalität der Methodik meiner englischen wie meiner deutschen Arbeit. 